\title{
Prediction of Mortality Using Different COPD Risk Assessments - A I2-Year Follow-Up
}

This article was published in the following Dove Press journal:

International Journal of Chronic Obstructive Pulmonary Disease

\author{
Åsa Athlin' \\ Maaike Giezeman ${ }^{1,2}$ \\ Mikael Hasselgren' \\ Scott Montgomery ${ }^{3-5}$ \\ Karin Lisspers $\left(10^{6}\right.$ \\ Björn Ställberg $\mathbb{D}^{6}$ \\ Christer Janson $\mathbb{1 D}^{7}$ \\ Josefin Sundh ${ }^{8}$
}

'School of Medical Sciences, Faculty of Medicine and Health, Örebro University, Örebro, Sweden; ${ }^{2}$ Centre for Clinical Research, Region Värmland, Karlstad, Sweden; ${ }^{3}$ Clinical Epidemiology and Biostatistics, School of Medical Sciences, Örebro University, Örebro, S-70I 82, Sweden; ${ }^{4}$ Clinical Epidemiology Division, Department of Medicine, Karolinska Institutet, Stockholm, Sweden;

${ }^{5}$ Department of Epidemiology and Public Health, University College, London, UK;

${ }^{6}$ Department of Public Health and Caring Sciences, Family Medicine and Preventive Medicine, Uppsala University, Uppsala, Sweden; ${ }^{7}$ Department of Medical Sciences, Respiratory, Allergy \& Sleep Research, Uppsala University, Uppsala, Sweden; ${ }^{8}$ Department of Respiratory Medicine, School of Medical Sciences, Faculty of Medicine and Health, Örebro University, Örebro, Sweden
Correspondence: Åsa Athlin

Vallgatan 17, Fjugesta, S-716 3I, Sweden Tel +4670 2265976

Email asa.athlin@regionorebrolan.se
Purpose: A multidimensional approach in the risk assessment of chronic obstructive pulmonary disease (COPD) is preferable. The aim of this study is to compare the prognostic ability for mortality by different COPD assessment systems; spirometric staging, classification by GOLD 2011, GOLD 2017, the age, dyspnea, obstruction (ADO) and the dyspnea, obstruction, smoking, exacerbation (DOSE) indices.

Patients and Methods: A total of 490 patients diagnosed with COPD were recruited from primary and secondary care in central Sweden in 2005. The cohort was followed until 2017. Data for categorization using the different assessment systems were obtained through questionnaire data from 2005 and medical record reviews between 2000 and 2003. Kaplan-Meier survival analyses and Cox proportional hazard models were used to assess mortality risk. Receiver operating characteristic curves estimated areas under the curve (AUC) to evaluate each assessment systems' ability to predict mortality.

Results: By the end of follow-up, $49 \%$ of the patients were deceased. The mortality rate was higher for patients categorized as stage 3-4, GOLD D in both GOLD classifications and those with a DOSE score above 4 and ADO score above 8 . The ADO index was most accurate for predicting mortality, AUC 0.79 (95\% CI $0.75-0.83)$ for all-cause mortality and 0.80 (95\% CI $0.75-0.85)$ for respiratory mortality. The AUC values for stages $1-4$, GOLD 2011, GOLD 2017 and DOSE index were 0.73, 0.66, 0.63 and 0.69, respectively, for allcause mortality.

Conclusion: All of the risk assessment systems predict mortality. The ADO index was in this study the best predictor and could be a helpful tool in COPD risk assessment.

Keywords: chronic obstructive pulmonary disease, GOLD classification, ADO index, DOSE index, prediction, mortality

\section{Introduction}

Chronic obstructive pulmonary disease (COPD) is one of the most common chronic diseases in Sweden with a prevalence of $6-10 \%$ in the adult population. ${ }^{1,2}$ Globally COPD is estimated to be the third most prevalent cause of death. ${ }^{3}$ In COPD a multidimensional risk assessment is preferable. Several factors such as airflow limitation, dyspnea, patient health status and exacerbations are all associated with increased mortality in patients with COPD. ${ }^{4-8}$ When the Global Initiative for Chronic Obstructive Lung Disease (GOLD) recommendations were launched in 1998, disease severity was based solely on lung function in stages $1-4$, expressed as forced expiratory volume in 1 second as a percentage of predicted value $\left(\mathrm{FEV}_{1} \%\right.$ pred). ${ }^{9}$ In 2011 a major revision of the severity classification occurred, including not only airflow limitation but also patients' symptoms and exacerbations. Combination of these factors distinguished four groups of 
patients; ABCD. ${ }^{10}$ Symptoms, or health status, were assessed by either of the modified Medical Research Council dyspnea scale (mMRC), COPD Assessment Test (CAT) or Clinical COPD Questionnaire (CCQ). ${ }^{11-13}$

The purposes of the classification from 2011 were to predict mortality as well as to individualize treatment. ${ }^{11}$ However, GOLD 2011 did not predict mortality more accurately than the spirometric grading. ${ }^{14-17}$ In 2017 a refined GOLD recommendation separated the spirometric grading 1-4 from the ABCD groups. In these current guidelines, the $\mathrm{FEV}_{1} \%$ pred grades airflow limitation severity and the ABCD groups based on symptoms and exacerbations serve as guidance of medical treatment. This multidimensional approach to COPD assessment is today a clinical standard and helps to personalize COPD treatment. ${ }^{18}$ However, a study based on a cohort from the United States found that prediction of all-cause mortality was lower for GOLD 2017 ABCD groups compared with the GOLD 2011 classification. $^{19}$ Furthermore, two recent studies concluded that mortality was only better predicted by GOLD 2017 compared to GOLD 2011 when divided into 16 subgroups (1A4D). ${ }^{20,21}$ These studies are mainly of patients treated in hospital outpatient clinics.

There are various multidimensional risk assessment instruments for COPD. ${ }^{22}$ The dyspnea, obstruction, smoking, exacerbation (DOSE); age, dyspnea, obstruction (ADO) and body mass index, obstruction, dyspnea, exercise (BODE) indices are three other major risk assessment systems. ${ }^{23-25}$ The DOSE index combines the value from the mMRC with obstruction ( $\mathrm{FEV}_{1} \%$ pred), smoking status and exacerbation rate in the previous year. The DOSE index score is a better predictor of mortality than each component by itself. ${ }^{26}$ The ADO index, derived from the BODE index and later updated in 2012 is also shown to predict mortality. ${ }^{27-29}$ ADO includes age, dyspnea and obstruction are assessed in the same way as in the DOSE index.

To our knowledge, there is still no comparison of the predictive properties of the different GOLD classifications, the ADO and DOSE indices, and no study comparing these in a cohort comprising mainly primary care patients.

The aim of this study is to compare the prognostic ability of the different COPD classifications and risk assessments; spirometric grading, classification by GOLD 2011, GOLD 2017, the ADO index and the DOSE index, in a cohort of mainly primary care patients in central Sweden.

\section{Patients and Methods}

\section{Study Subjects and Design}

This is an observational study where the population was sampled from the PRAXIS study COPD cohort created in 2005. Patients were enrolled from the seven central hospitals, seven randomly selected district hospitals and 56 randomly selected primary health care centers (PHCC) in seven county councils in central Sweden. A list of all patients aged 18-75 years diagnosed with COPD (ICD-10 code J44) in the medical records during the period of 2000-2003 was obtained at each unit. From these lists, patients were randomly selected at each site using an internet-based program. In total, 1548 patients were selected.

\section{Methods}

Data were collected in 2005 by a self-completed questionnaire and medical record review. The questionnaire response rate was $76 \%$. Of the responders, $98 \%$ gave permission to review their medical records. The questionnaire included information on age, sex, smoking status, exacerbations and the Swedish versions of the mMRC scale and CCQ. Exacerbations were identified in the questionnaire as emergency visits or a course of oral corticosteroids due to worsening of COPD during the previous six months. Data on lung function and comorbidity were retrieved by review of medical records for the time period 2000-2003. This was accomplished by two research nurses. All data needed for classification according to different assessment systems were collected at baseline. This was complete for 490 patients (Figure 1).

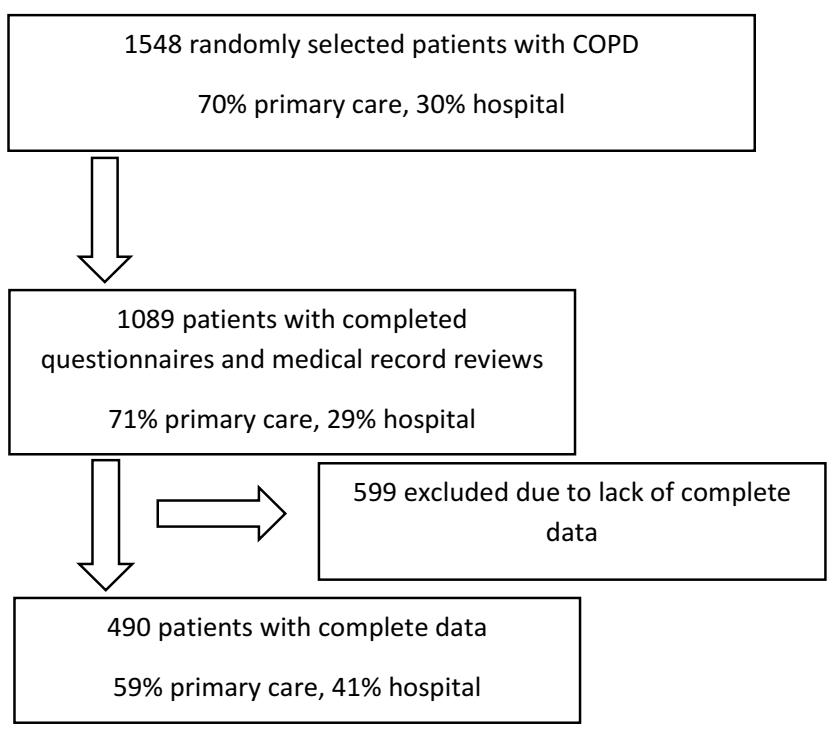

Figure I Flowchart patient selection. Abbreviation: COPD, chronic obstructive pulmonary disease. 
Heart disease was defined as a recorded diagnosis of ischemic heart disease or heart failure, diabetes as type 1 or 2 diabetes mellitus, and depression as a diagnosis in combination with antidepressant drug treatment. The cohort was followed for 12 years, from 2005 to 2017 . Mortality data, until August 31 2017, were obtained from the Swedish National Board of Health and Welfare. Causespecific mortality was categorized as respiratory mortality (including respiratory infections), cardiovascular mortality and other causes of death (including all types of cancer).

\section{Assessment Systems}

The various components of the different COPD assessment systems are summarized in Table 1.

Stage 1-4-Lung function from spirometry was expressed as $\mathrm{FEV}_{1 \%}$ predicted using the European Community for Steel and Coal reference values. ${ }^{30}$ Stage $1: \geq 80 \%$ pred, stage 2: $50-79 \%$ pred, stage $3: 30-49 \%$ pred and stage $4:<30 \%$ pred.

mMRC - Self-reported dyspnea. This dyspnea scale is a questionnaire with five statements ( 0 to 4$)$ about perceived breathlessness, the higher the more severe. ${ }^{12}$

CCQ - Self-reported health status. The questionnaire consists of 10 items concerning three domains; symptoms, mental state and functional state, based on experiences the previous week. Each item is scored from 0 to 6 . All scores are added and the sum divided by ten. The total mean CCQ-score varies from 0 (very good control) to 6 (extremely poor control). ${ }^{6,11}$

GOLD 2011 - Classification into groups ABCD by combining $\mathrm{FEV}_{1} \%$ pred, number of exacerbations previous year and self-reported symptoms by mMRC and/or CCQ.

GOLD 2017 - Classification into groups ABCD by combining exacerbations previous year and self-reported symptoms by mMRC and/or CCQ, both available at the time of baseline data collection.
DOSE index $-\mathrm{A}$ score is calculated ( $0-8$ points). A higher score indicates a higher burden of disease. Patients were categorized into three groups by score $<4,4-5$ and $6-8$ points, respectively, according to the original paper. ${ }^{23}$

ADO index - Data for calculation of the updated ADO index were used. $^{29}$ A score is calculated (0-14 points) where a higher score indicates a more severe condition. Patients were categorized into four groups by score $0-5$, $6-7,8-9$ and $\geq 10$ points. To enable comparison of results, the choice of groups was chosen based on a recent study. ${ }^{31}$

For calculation of groups according to GOLD, an mMRC score $\geq 2$ or CCQ $\geq 1$ was defined as a high symptom score. ${ }^{32}$ Exacerbation data for the previous six months were used to estimate the annual exacerbation rate. For the GOLD classification, zero exacerbations in six months corresponded to zero to one exacerbation in a year. One or more exacerbations in six months were considered as a frequent exacerbator with two exacerbations in a year. For the DOSE index, zero exacerbations were classified as a score of zero, one or two exacerbations as a score of one and three or more exacerbations as a score of two.

\section{Analysis}

All statistical analyses were performed using IBM SPSS Statistics 25. Cross-tabulations were used to examine baseline data and mortality frequencies. For survival analyses, Kaplan Meier curves were constructed. Cox proportional hazard models were used to calculate crude and adjusted hazard ratios (HR) and 95\% CI for the association of each risk assessment system with all-cause and cause-specific mortality (respiratory and cardiovascular). Stratification and multiplicative interaction by sex and each relevant variable were performed. Comparison of the different assessment systems in predictive

Table I Included Components of Different COPD Assessment Systems

\begin{tabular}{|c|c|c|c|c|c|c|}
\hline & \multirow{2}{*}{$\begin{array}{c}\text { FEV }, \% \\
\text { Predicted }\end{array}$} & \multicolumn{2}{|c|}{ Symptoms } & \multirow{2}{*}{$\begin{array}{c}\text { Exacerbation Frequency } \\
\text { Recent Year }\end{array}$} & \multirow{2}{*}{$\begin{array}{l}\text { Smoking } \\
\text { Status }\end{array}$} & \multirow[t]{2}{*}{ Age } \\
\hline & & Dyspnea mMRC-Scale & $\begin{array}{c}\text { Health Status } \\
\text { CCQ }\end{array}$ & & & \\
\hline GOLD stage I-4 & + & & & & & \\
\hline GOLD 201I & + & + & + & + & & \\
\hline GOLD 2017 & & + & + & + & & \\
\hline DOSE index & + & + & & + & + & \\
\hline ADO index & + & + & & & & + \\
\hline
\end{tabular}

Abbreviations: $\mathrm{FEV}, \%$, forced expiratory volume in I second as percentage of predicted value; mMRC, modified Medical Research Council dyspnea scale; CCQ, Clinical COPD Questionnaire; GOLD, Global Initiative for Chronic Obstructive Lung Disease; DOSE, dyspnea, obstruction, smoking, exacerbation; ADO, age, dyspnea, obstruction. 
ability was calculated using receiver operating characteristic curves (ROC). The overall ability to predict mortality is expressed as area under the curve (AUC). P-values $<0.05$ were considered statistically significant.

\section{Ethics}

The study was performed in accordance with the principles stated in the Declaration of Helsinki. All participants gave written informed consent. The study was approved by the regional ethical board in Uppsala (EPN), Sweden, Dnr 2004 M-445 and Dnr 2010/090.

\section{Results}

\section{Patient Characteristics}

In summary, $58 \%$ were women and $59 \%$ of the patients were recruited from primary care. In the entire cohort median age was 64 years (IQR 59-69), median postbronchodilator $\mathrm{FEV}_{1} / \mathrm{FVC}$ was 0.58 (IQR 48-70) and median $\mathrm{FEV}_{1} \%$ pred was 63 (IQR 44-81). The majority of the patients had an mMRC-score in the range 2-4, indicating daily dyspnea to some extent and $63 \%$ had less than 2 exacerbations/year (Table 2). The median ADO score was 7.0 (IQR 5.0-9.0) and the median DOSE score was 2.0 (IQR 1.0-4.0).

\section{Predictive Abilities}

The COPD population was followed during 12 years. Of 490 patients included in $2005,49 \%$ were deceased in 2017. Mortality rate was higher for patients categorized as having a more severe disease, regardless of risk assessment system (Figure 2).

The cumulative survival is visualized by Kaplan-Meier curves (Figure 3). Higher ADO or DOSE score and the more severely classified as stages 1-4 or GOLD A-D are associated with poorer survival.

Group C had a limited number of subjects, 13 and 7, respectively, for GOLD 2011 and GOLD 2017. These subjects have therefore been excluded from curves and in presented calculations of hazard ratio. Regardless of risk assessment system, the mortality risk presented as hazard ratio indicates an increasing all-cause and respiratory mortality with more severe disease. After adjustment for age and heart disease, no significant differences were seen (data not shown). The same tendency was shown for cardiovascular death $(\mathrm{n}=61)$, but with lower amplitudes (Table 3).
Stratification and interaction analysis by sex showed no effect modification by sex for any of the COPD risk assessments (data not shown). Comparison of the predictive ability of mortality for all the risk assessment systems is shown in Figure 4. Area under the curve was highest for the ADO index for all-cause mortality. The classification in stages 1-4 and the ADO index were significantly better predictors of mortality than GOLD 2017. ADO also had the highest AUC for respiratory mortality (Figure 5). For cardiovascular mortality, AUC was below 0.5 for all risk assessment systems (data not shown).

\section{Discussion}

This study examines the ability of different COPD risk assessment systems in predicting all-cause mortality in a real-world setting during a 12-year follow-up. The primary finding was that overall, all risk assessment systems, predicted all-cause mortality and respiratory mortality. The secondary finding is that the ADO index had the most accurate predictive ability.

Our study confirms previous study results that GOLD 2017 does not predict mortality better than earlier classifications of $\mathrm{COPD}^{19-21}$ and that the ADO index predicts mortality more accurately than the DOSE index. ${ }^{27,28}$ However, we have expanded the follow-up period to 12 years, and we are not aware of any studies comparing all GOLD classifications, the DOSE index and the ADO index. We also find it very important that we could replicate previous findings in a cohort of mainly primary care patients.

Two previous studies found the best predictive ability for GOLD 2017 when airflow limitation was added to symptoms and exacerbations, ie, creating 16 subgroups $(1 \mathrm{~A}-4 \mathrm{D}) \mathrm{r}^{21,22}$ Thus, airflow limitation as a prognostic factor seems important. This confirms the recommendation from GOLD to use $\mathrm{FEV}_{1} \%$ pred for prognosis and symptoms/exacerbations as a base of initial treatment.

Most COPD patients are managed in primary care, and the multidimensional instruments were created to facilitate for general practitioners who need a non-time consuming yet reliable strategy in COPD assessment. Identifying patients at high risk will make it easier to allocate time and resources to the patients with a higher burden of disease. The forerunner in multi-component assessment, the BODE index has convincingly shown superiority in predicting mortality. ${ }^{33}$ However, the inclusion of the result of a 6 MWT (six-minute walking test) can make it less 
Table 2 Patient Characteristics at Baseline and Characteristics of Alive/Deceased 2017

\begin{tabular}{|c|c|c|c|}
\hline & $\begin{array}{l}\text { All Patients } \\
\text { n (\%) }\end{array}$ & $\begin{array}{l}\text { Dead } 2017 \\
\text { n (\%) }\end{array}$ & $\begin{array}{l}\text { Alive } 20 \text { I } 7 \\
\text { n (\%) }\end{array}$ \\
\hline All patients & 490 & $24 \mid(49)$ & $249(5 \mathrm{I})$ \\
\hline \multicolumn{4}{|l|}{ Sex } \\
\hline Male & $208(42)$ & $112(46)$ & $96(39)$ \\
\hline Female & $282(58)$ & $129(54)$ & $153(6 \mid)$ \\
\hline \multicolumn{4}{|l|}{ Care level } \\
\hline Primary care & $289(59)$ & $116(48)$ & $173(70)$ \\
\hline Hospital care & $20 I(4 I)$ & $125(52)$ & $76(30)$ \\
\hline \multicolumn{4}{|l|}{ Age } \\
\hline$<50$ & $39(8)$ & $2(1)$ & $37(15)$ \\
\hline $50-59$ & II 5 (23) & $34(14)$ & $81(33)$ \\
\hline $60-69$ & $245(50)$ & $140(58)$ & $105(42)$ \\
\hline$\geq 70$ & $91(19)$ & $65(27)$ & $26(10)$ \\
\hline \multicolumn{4}{|l|}{ Smoking habits } \\
\hline Non-smoker & $354(72)$ & I79 (74) & $175(70)$ \\
\hline Current smoker & $136(28)$ & $62(26)$ & $74(30)$ \\
\hline \multicolumn{4}{|l|}{ Lung function (Stage I-4) } \\
\hline $\mathrm{FEV}_{1} \%$ pred $\geq 80 /$ Stage I & $128(26)$ & $27(\mathrm{II})$ & $|0|(4 I)$ \\
\hline $\mathrm{FEV}_{1} \%$ pred $50-79 /$ Stage 2 & $205(42)$ & $95(39)$ & II 0 (44) \\
\hline $\mathrm{FEV}_{1} \%$ pred $30-49 /$ Stage 3 & II 8 (24) & $87(36)$ & $31(12)$ \\
\hline $\mathrm{FEV}_{1} \%$ pred $<30 /$ Stage 4 & $39(8)$ & $32(13)$ & $7(3)$ \\
\hline \multicolumn{4}{|l|}{ mMRC-score } \\
\hline $0-1$ & $208(42)$ & $62(26)$ & $146(59)$ \\
\hline $2-4$ & $282(58)$ & $179(74)$ & $103(4 I)$ \\
\hline \multicolumn{4}{|l|}{ CCQ-score } \\
\hline$<1$ & $97(20)$ & $25(10)$ & $72(29)$ \\
\hline$\geq 1$ & $393(80)$ & $216(90)$ & I77 (7I) \\
\hline \multicolumn{4}{|l|}{ Exacerbations previous year } \\
\hline $0-1$ & $305(63)$ & $130(54)$ & $175(70)$ \\
\hline $2-3$ & $124(25)$ & $68(28)$ & $56(23)$ \\
\hline$>3$ & $61(12)$ & $43(18)$ & $18(7)$ \\
\hline \multicolumn{4}{|l|}{ BMI } \\
\hline$<20$ & $57(12)$ & $42(18)$ & $15(6)$ \\
\hline $20-24.9$ & $164(34)$ & $78(33)$ & $86(35)$ \\
\hline $25-29.9$ & $176(36)$ & $69(29)$ & $107(43)$ \\
\hline$\geq 30$ & $87(18)$ & $48(20)$ & $39(16)$ \\
\hline Heart disease & $109(22)$ & $76(32)$ & $33(13)$ \\
\hline Depression & $64(13)$ & $29(12)$ & $35(14)$ \\
\hline Diabetes & $37(8)$ & $26(11)$ & II (4) \\
\hline
\end{tabular}

Abbreviations: FEVI\%, forced expiratory volume in I second as percentage of predicted value; mMRC, modified Medical Research Council dyspnoea scale; CCQ, Clinical COPD Questionnaire; BMI, body mass index.

convenient in clinical practice due to the need for an extra health care visit to have this completed. This instrument was not investigated in our study.
The ADO (derived from the BODE index) and DOSE indices are simple to use and have shown predictive abilities for mortality. ${ }^{26,27}$ This is concordant 

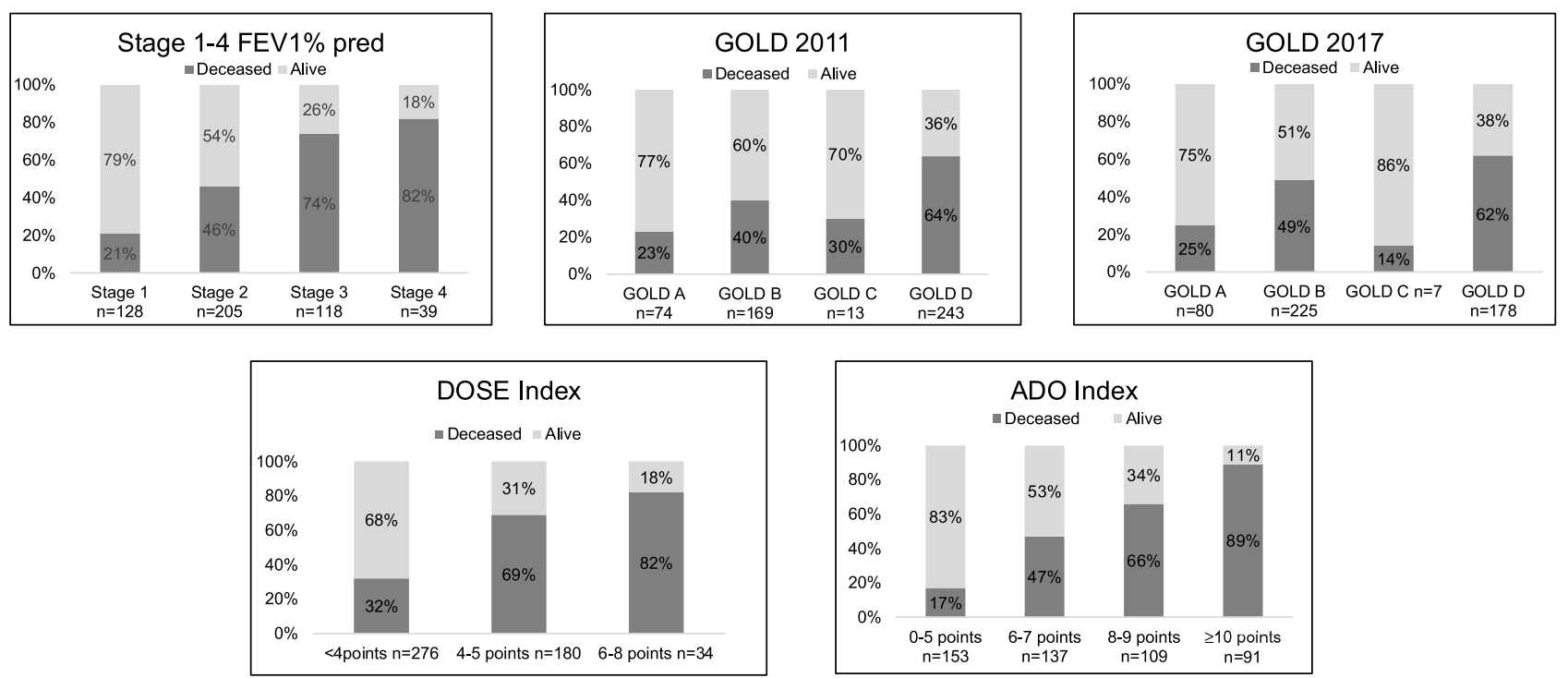

Figure 2 Mortality rate in each group for each assessment system. Stage refers to lung function, stage I-FEV $\%$ pred $\geq 80$, stage $2-\mathrm{FEV}, \%$ pred $50-79$, stage $3-\mathrm{FEV}, \%$ pred 30-49, stage 4-FEV,\% pred $<30$.

Abbreviations: GOLD, Global Initiative for Chronic Obstructive Lung Disease; DOSE, dyspnoea, obstruction, smoking, exacerbation; ADO, age, dyspnoea, obstruction.
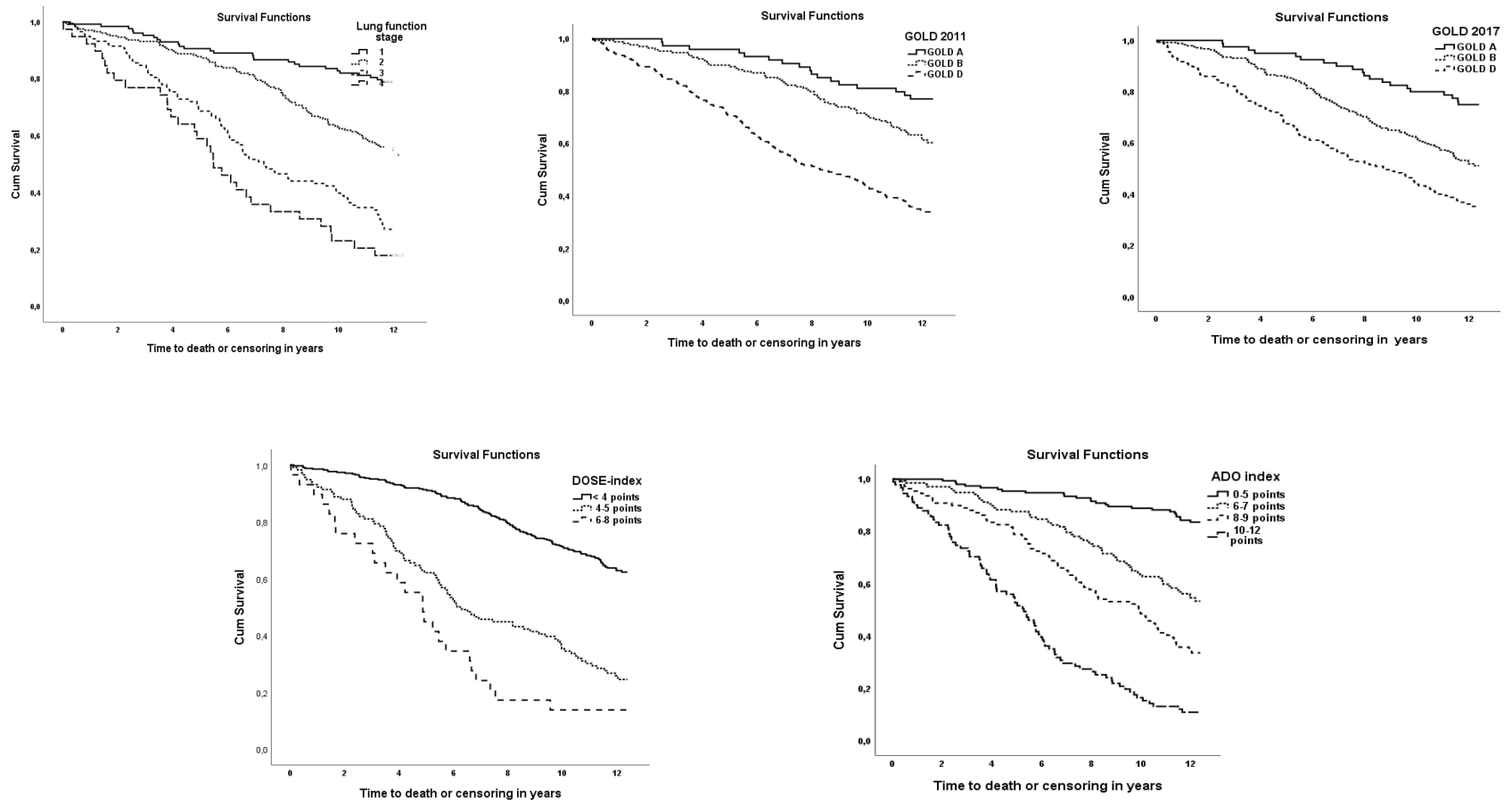

Figure 3 Cumulative I2-year survival for different COPD assessment systems. Lung function, stage I-FEV $\%$ pred $\geq 80$, stage 2 -FEV $1 \%$ pred $50-79$, stage $3-\mathrm{FEV}, \%$ pred $30-49$, stage $4-\mathrm{FEV}_{1} \%$ pred $<30$.

Abbreviations: GOLD, Global Initiative for Chronic Obstructive Lung Disease; DOSE, dyspnoea, obstruction, smoking, exacerbation; ADO, age, dyspnoea, obstruction.

with our findings of increasing hazard ratio along with increasing index scores. In the original publication with creation of the ADO index, as for the updated version, 3-year mortality was calculated. ${ }^{24,29}$ A later published Swiss study reported ADO index to be an excellent predictor of 2-year all-cause mortality in a primary care setting. ${ }^{34}$ In another primary care cohort, the ADO index showed good discrimination in predicting 3-year mortality with AUC $0.73 .^{31}$ With our results, presenting a twelve-year follow-up, this could imply that prediction by the ADO index is reliable even for a longer period of time. 
Table 3 Hazard Ratio for All-Cause, Respiratory and Cardiovascular Mortality. GOLD Group C Excluded

\begin{tabular}{|c|c|c|c|c|c|c|}
\hline & \multicolumn{2}{|c|}{ All-Cause Mortality $n=24$ I } & \multicolumn{2}{|c|}{ Respiratory Mortality $n=107$} & \multicolumn{2}{|c|}{ Cardiovascular Mortality $n=61$} \\
\hline & HR (95\% Cl) & $\mathbf{p}$ & HR (95\% CI) & $\mathbf{p}$ & HR (95\% Cl) & $\mathbf{p}$ \\
\hline \multicolumn{7}{|l|}{ GOLD Stage } \\
\hline 1 & Ref & & Ref & & Ref & \\
\hline 2 & $2.53(1.61-3.89)$ & $<0.000$ I & $3.45(1.43-8.32)$ & 0.006 & $2.14(1.00-4.56)$ & 0.048 \\
\hline 3 & $5.53(3.59-8.53)$ & $<0.000$ I & $13.00(5.54-30.49)$ & $<0.0001$ & $4.06(1.87-8.87)$ & $<0.001$ \\
\hline 4 & $7.82(4.67-13.10)$ & $<0.0001$ & $28.19(11.56-68.76)$ & $<0.0001$ & $2.10(0.57-7.79)$ & 0.27 \\
\hline \multicolumn{7}{|l|}{ GOLD 20II } \\
\hline A & Ref & & Ref & & Ref & \\
\hline B & $1.92(1.13-3.28)$ & $<0.02$ & $3.05(0.90-10.35)$ & 0.074 & $2.17(0.73-6.43)$ & 0.17 \\
\hline $\mathrm{D}$ & $4.12(2.49-6.80)$ & $<0.000 \mathrm{I}$ & $12.73(4.02-40.26)$ & $<0.0001$ & $4.21(1.50-11.80)$ & 0.006 \\
\hline \multicolumn{7}{|l|}{ GOLD 2017} \\
\hline A & Ref & & Ref & & Ref & \\
\hline B & $2.32(1.44-3.73)$ & $<0.01$ & $5.85(1.81-18.86)$ & 0.003 & $2.24(0.94-5.35)$ & 0.07 \\
\hline$D$ & $3.58(2.22-5.77)$ & $<0.0001$ & $13.32(4.18-42.48)$ & $<0.0001$ & $2.46(1.00-6.05)$ & 0.05 \\
\hline \multicolumn{7}{|l|}{ DOSE index } \\
\hline$<4$ & Ref & & Ref & & Ref & \\
\hline $4-5$ & $3.13(2.38-4.12)$ & $<0.000 \mathrm{I}$ & $6.944 .|9-||.5|)$ & $<0.0001$ & $2.49(1.50-4.16)$ & $<0.001$ \\
\hline $6-8$ & $5.74(3.73-8.82)$ & $<0.0001$ & $22.63(12.48-41.05)$ & $<0.0001$ & $0.61(0.082-4.49)$ & 0.63 \\
\hline \multicolumn{7}{|l|}{ ADO index } \\
\hline $0-5$ & Ref & & Ref & & Ref & \\
\hline $6-7$ & $3.4 I(2.15-5.43)$ & $<0.000$ I & $4.86(1.80-13.08)$ & $<0.002$ & $3.17(1.39-7.26)$ & 0.006 \\
\hline $8-9$ & $5.99(3.80-9.46)$ & $<0.0001$ & $12.82(4.98-33.02)$ & $<0.0001$ & $4.84(2.11-11.08)$ & $<0.0001$ \\
\hline$\geq 10$ & $14.10(8.93-22.21)$ & $<0.0001$ & 45.81 (I8.18-II5.43) & $<0.0001$ & $7.57(3.16-18.12)$ & $<0.001$ \\
\hline
\end{tabular}

Abbreviations: HR, hazard ratio; $\mathrm{Cl}$, confidence interval; GOLD, Global Initiative for Chronic Obstructive Lung Disease; DOSE, dyspnea, obstruction, smoking, exacerbation; ADO, age, dyspnea, obstruction.

Comparison of multidimensional indices in previous publications, including five-year data from our own cohort, found the original ADO index to be a better predictor of mortality than the DOSE index in primary care patients with COPD. ${ }^{27,28}$ This suggestion is substantiated in our study where ROC curves displayed the highest area under the curve for the ADO index, 0.79 for all-cause mortality and 0.80 for respiratory cause of mortality. An AUC of $>0.9$ is considered excellent, 0.8-0.89 good, 0.7-0.79 fair/modest and 0.5-0.69 poor/ marginal. ${ }^{35,36}$ With this definition, all assessment systems but GOLD 2017 are at least modest in predicting respiratory cause of death (AUC $>0.7$ ) and slightly less accurate for prediction of all-cause mortality. Nevertheless, in both cases, a significant difference was seen for, on one hand, the ADO index and assessment by stages $1-4$, and, on the other hand, GOLD 2017, indicated by non-overlapping confidence intervals, emphasizing the importance of lung function as a prognostic factor. Obstruction, also being age-related is recommended by the most recent GOLD document to be used for prognosis. ${ }^{18}$ When the ADO index was derived, Puhan et al found age, $\mathrm{FEV}_{1}$ and dyspnea among the strongest predictors of death in patients with COPD. ${ }^{24}$ In our adjusted results, no statistically significant differences in hazard ratios were seen for any of the assessment systems. One might have expected a disparity since older age is an undeniable contributor to mortality. Age may be a large contributor to the total ADO score ( 7 points if age $>80$ ). An argument could be that this would weaken the discrimination since older age on its own could give a high-risk score. In our cohort being relatively young, (median age 64 years) and with a moderate decline in lung function (median $\mathrm{FEV}_{1} \%$ pred 63) the index turned out better in comparison. This could indicate the strength in a multidimensional approach even when several factors are age-related. 


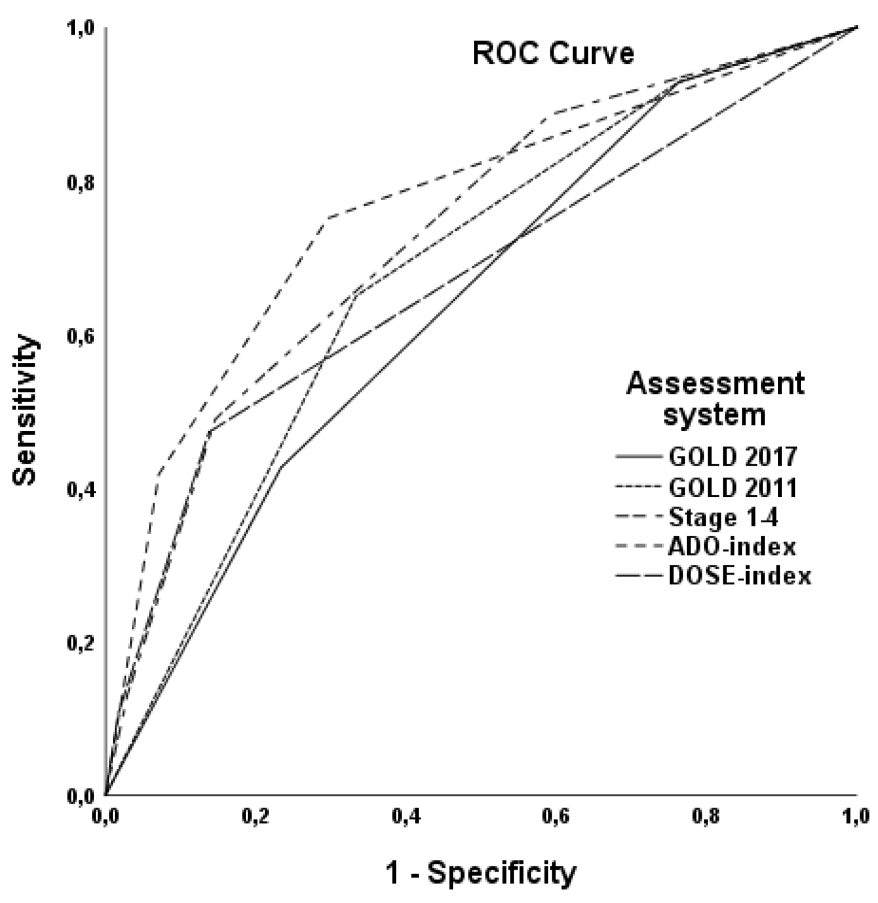

\begin{tabular}{|l|l|}
\hline \multicolumn{1}{|c|}{$\begin{array}{c}\text { Assessment } \\
\text { system }\end{array}$} & AUC (95\% CI) \\
\hline ADO index & $0.79(0.75-0.83)$ \\
\hline Stage 1-4 & $0.73(0.69-0.78)$ \\
\hline DOSE index & $0.69(0.64-0.74)$ \\
\hline GOLD 2011 & $0.66(0.61-0.72)$ \\
\hline GOLD 2017 & $0.63(0.57-0.68)$ \\
\hline
\end{tabular}

Figure 4 Receiver-operator characteristics for different COPD assessment systems as predictors of all-cause mortality. Area under the curve (AUC) for each assessment system presented. Stage I-4 refers to lung function.

Abbreviations: $\mathrm{Cl}$, confidence interval; GOLD, Global Initiative for Chronic Obstructive Lung Disease; DOSE, dyspnoea, obstruction, smoking, exacerbation; ADO, age, dyspnoea, obstruction.

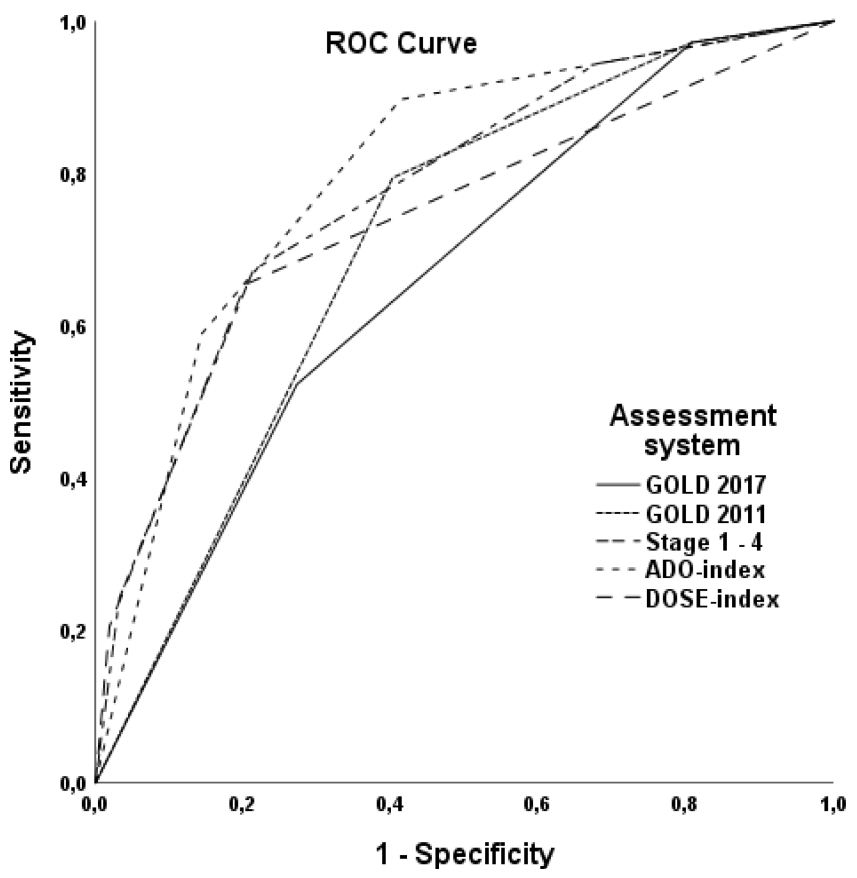

\begin{tabular}{|l|l|}
\hline \multicolumn{1}{|c|}{$\begin{array}{c}\text { Assessment } \\
\text { system }\end{array}$} & AUC (95\% Cl) \\
\hline ADO index & $0.80(0.75-0.85)$ \\
\hline Stage 1-4 & $0.78(0.72-0.83)$ \\
\hline DOSE index & $0.77(0.71-0.82)$ \\
\hline GOLD 2011 & $0.70(0.65-0.75)$ \\
\hline GOLD 2017 & $0.66(0.61-0.72)$ \\
\hline
\end{tabular}

Figure 5 Receiver-operator characteristics for different COPD assessment systems as predictors of respiratory mortality. Area under the curve (AUC) for each assessment system presented. Stage I-4 refers to lung function.

Abbreviations: $\mathrm{Cl}$, confidence interval; GOLD, Global Initiative for Chronic Obstructive Lung Disease; DOSE, dyspnoea, obstruction, smoking, exacerbation; ADO, age, dyspnoea, obstruction. 
There was a clear tendency that most risk assessment systems also predicted cardiovascular mortality, although with lower amplitudes and fewer statistically significant associations than for all-cause and respiratory mortality. This is consistent with the fact that comorbid heart disease is common in COPD, and also a common cause of death. ${ }^{37}$ Using ROC-curves, AUC was below 0.5 for all risk assessment systems indicating that the association may not be of clinical significance.

\section{Strengths and Limitations}

Main strengths are the long follow-up time, and the realworld data reflecting what is actually accomplished at the different units. Limitations include that several components necessary for categorization into the different assessment systems could be missing. In this study, a substantial number of patients were not able to be included mainly because of missing spirometry data, which could be a potential cause of selection bias. Self-reported data such as a number of exacerbations could be subject to recall bias. An attrition analysis showed that patients excluded due to missing data were the same age and sex as included patients (excluded mean age 65 years). When analyzing age groups, exclusion in age group $>70$ was significantly higher (data not shown). One must consider the risk of the excluded older group having a generally higher burden of disease. We believe that our reported strong association of ADO index with mortality was not due to selection bias, as it would rather have been even stronger if the excluded predominantly older patients had been involved.

Annual exacerbation rates were estimated from patientreported data. The questionnaire requests exacerbations and emergency visits during the past six months, to minimize recall bias. Data on exacerbations the past twelve months were extrapolated from this information. This is explained by the fact that when the PRAXIS study was initiated neither the GOLD 2011/2017 assessment nor the DOSE index had been created. Patient questionnaires were distributed evenly throughout the year to minimize the risk of collecting data predominantly during the winter months when the risk of exacerbations is more likely to be higher. We believe that this extrapolation does not affect the results.

Convenient measures of patient-reported symptoms recommended by GOLD are CCQ and CAT. Today CAT is most commonly used in clinical practice. At the time data were collected in 2005, CAT did not exist. However,
CCQ and CAT are well correlated to each other ${ }^{38,39}$ which enables the use of CCQ.

According to GOLD, a high level of symptoms could also be assessed using mMRC. We chose to combine the two scales CCQ and mMRC, as a high symptom level may be detected by only one of the instruments. In our material, 403 patients (82\%) had a high symptom level using both CCQ and mMRC, and 393 (80\%) had a high symptom level using only CCQ. Thus, our opinion is that using only CCQ would not have changed the results.

We chose to exclude group $\mathrm{C}$ from statistical calculations due to the small number of patients because accuracy would have been affected. $^{40}$ In addition, repeating the analyses with inclusion of the group C patients together with group D did not change the results (data not shown).

\section{Conclusion}

In this 12-year follow-up, out of all risk assessment systems to predict mortality, the ADO index was the most accurate, followed by an assessment by lung function. We conclude that the GOLD recommendation to use lung function for prognosis is appropriate and that the ADO index can be a useful tool for COPD risk assessment in clinical practice.

\section{Acknowledgments}

The authors wish to thank all participating centers and Ulrike Spetz-Nyström and Eva Manell at the Department of Medical Sciences, Respiratory, Allergy \& Sleep Research, Uppsala University, for reviewing the patient records.

\section{Disclosure}

Dr Karin Lisspers reports personal fees from Payments for lectures and educational activities, personal fees from Advisory board, outside the submitted work. The authors report no other conflicts of interest in this work.

\section{References}

1. Backman H, Eriksson B, Ronmark E, et al. Decreased prevalence of moderate to severe COPD over 15 years in northern Sweden. Respir Med. 2016;114:103-110. doi:10.1016/j.rmed.2016.03.013

2. Stallberg B, Janson C, Johansson G, et al. Management, morbidity and mortality of COPD during an 11-year period: an observational retrospective epidemiological register study in Sweden (PATHOS). Prim Care Respir J. 2014;23(1):38-45. doi:10.4104/ pcrj.2013.00106 
3. Lozano R, Naghavi M, Foreman K, et al. Global and regional mortality from 235 causes of death for 20 age groups in 1990 and 2010: a systematic analysis for the Global Burden of Disease Study 2010. Lancet. 2012;380(9859):2095-2128. doi:10.1016/S0140-6736(12) 61728-0

4. Nishimura K, Izumi T, Tsukino M, Oga T. Dyspnea is a better predictor of 5-year survival than airway obstruction in patients with COPD. Chest. 2002;121(5):1434-1440. doi:10.1378/chest.121.5.1 434

5. Sundh J, Janson C, Lisspers K, Montgomery S, Stallberg B. Clinical COPD Questionnaire score (CCQ) and mortality. Int J Chron Obstruct Pulmon Dis. 2012;7:833-842. doi:10.2147/ COPD.S38119

6. Soler-Cataluna JJ, Martinez-Garcia MA, Roman Sanchez P, Salcedo E, Navarro M, Ochando R. Severe acute exacerbations and mortality in patients with chronic obstructive pulmonary disease. Thorax. 2005;60(11):925-931. doi:10.1136/thx.2005.040527

7. Mattila T, Vasankari T, Kanervisto M, et al. Association between allcause and cause-specific mortality and the GOLD stages 1-4: a 30year follow-up among Finnish adults. Respir Med. 2015;109 (8):1012-1018. doi:10.1016/j.rmed.2015.06.002

8. Celli BR. Predictors of mortality in COPD. Respir Med. 2010;104 (6):773-779. doi:10.1016/j.rmed.2009.12.017

9. Rabe KF, Hurd S, Anzueto A, et al. Global strategy for the diagnosis, management, and prevention of chronic obstructive pulmonary disease: GOLD executive summary. Am J Respir Crit Care Med. 2007;176(6):532-555. doi:10.1164/rccm.200703-456SO

10. Vestbo J, Hurd SS, Agusti AG, et al. Global strategy for the diagnosis, management, and prevention of chronic obstructive pulmonary disease: GOLD executive summary. Am J Respir Crit Care Med. 2013;187(4):347-365. doi:10.1164/rccm.201204-0596PP

11. van der Molen T, Willemse BW, Schokker S, Ten Hacken NH, Postma DS, Juniper EF. Development, validity and responsiveness of the Clinical COPD Questionnaire. Health Qual Life Outcomes. 2003;1:13. doi:10.1186/1477-7525-1-13

12. Bestall JC, Paul EA, Garrod R, Garnham R, Jones PW, Wedzicha JA. Usefulness of the Medical Research Council (MRC) dyspnoea scale as a measure of disability in patients with chronic obstructive pulmonary disease. Thorax. 1999;54(7):581-586. doi:10.1136/thx.5 4.7.581

13. Jones PW, Harding G, Berry P, Wiklund I, Chen WH, Kline Leidy N. Development and first validation of the COPD assessment test. Eur Respir J. 2009;34(3):648-654. doi:10.1183/09031936.00102509

14. Lange P, Marott JL, Vestbo J, et al. Prediction of the clinical course of chronic obstructive pulmonary disease, using the new GOLD classification: a study of the general population. Am J Respir Crit Care Med. 2012;186(10):975-981. doi:10.1164/rccm.201207$12990 \mathrm{C}$

15. Dusser D, Wise RA, Dahl R, et al. Differences in outcomes between GOLD groups in patients with COPD in the TIOSPIR ((R)) trial. Int J Chron Obstruct Pulmon Dis. 2016;11:133-145. doi:10.2147/ COPD.S97924

16. Soriano JB, Alfageme I, Almagro P, et al. Distribution and prognostic validity of the new global initiative for chronic obstructive lung disease grading classification. Chest. 2013;143(3):694-702. doi:10.1378/chest.12-1053

17. Soriano JB, Lamprecht B, Ramirez AS, et al. Mortality prediction in chronic obstructive pulmonary disease comparing the GOLD 2007 and 2011 staging systems: a pooled analysis of individual patient data. Lancet Respir Med. 2015;3(6):443-450. doi:10.1016/S22132600(15)00157-5

18. Vogelmeier CF, Criner GJ, Martinez FJ, et al. Global strategy for the diagnosis, management, and prevention of chronic obstructive lung disease 2017 report. GOLD Executive Summary Am j Respir Crit Care Med. 2017;195(5):557-582. doi:10.1164/rccm.2017010218PP
19. Criner RN, Labaki WW, Regan EA, et al. Mortality and exacerbations by global initiative for chronic obstructive lung disease groups ABCD: 2011 versus 2017 in the COPD Gene (R) cohort. Chronic Obstr Pulm Dis. 2019;6(1):64-73. doi:10.15326/jcopdf.6.1.201 8.0130

20. Gedebjerg A, Szepligeti SK, Wackerhausen LH, et al. Prediction of mortality in patients with chronic obstructive pulmonary disease with the new global initiative for chronic obstructive lung disease 2017 classification: a cohort study. Lancet Respir Med. 2018;6(3):204-212. doi:10.1016/S2213-2600(18)30002-X

21. Le LAK, Johannessen A, Hardie JA, et al. Prevalence and prognostic ability of the GOLD 2017 classification compared to the GOLD 2011 classification in a Norwegian COPD cohort. Int J Chron Obstruct Pulmon Dis. 2019;14:1639-1655. doi:10.2147/COPD.S194019

22. Dijk WD, Bemt L, Haak-Rongen S, et al. Multidimensional prognostic indices for use in COPD patient care. Syst Rev Respir Res. 2011;12:151. doi:10.1186/1465-9921-12-151

23. Jones RC, Donaldson GC, Chavannes NH, et al. Derivation and validation of a composite index of severity in chronic obstructive pulmonary disease: the DOSE index. Am J Respir Crit Care Med. 2009;180(12):1189-1195. doi:10.1164/rccm.200902-0271OC

24. Puhan MA, Garcia-Aymerich J, Frey M, et al. Expansion of the prognostic assessment of patients with chronic obstructive pulmonary disease: the updated BODE index and the ADO index. Lancet. 2009;374(9691):704-711. doi:10.1016/S0140-6736(09)61301-5

25. Celli BR, Cote CG, Marin JM, et al. The body-mass index, airflow obstruction, dyspnea, and exercise capacity index in chronic obstructive pulmonary disease. $N$ Engl J Med. 2004;350(10):1005-1012. doi:10.1056/NEJMoa021322

26. Sundh J, Janson C, Lisspers K, Stallberg B, Montgomery S. The Dyspnoea, Obstruction, Smoking, Exacerbation (DOSE) index is predictive of mortality in COPD. Prim Care Respir J. 2012;21 (3):295-301. doi:10.4104/pcrj.2012.00054

27. Jones RC, Price D, Chavannes NH, et al. Multi-component assessment of chronic obstructive pulmonary disease: an evaluation of the ADO and DOSE indices and the global obstructive lung disease categories in international primary care data sets. NPJ Prim Care Respir Med. 2016;26:16010. doi:10.1038/npjpcrm.2016.10

28. Morales DR, Flynn R, Zhang J, Trucco E, Quint JK, Zutis K. External validation of ADO, DOSE, COTE and CODEX at predicting death in primary care patients with COPD using standard and machine learning approaches. Respir Med. 2018;138:150-155. doi:10.1016/j.rmed.2018.04.003

29. Puhan MA, Hansel NN, Sobradillo P, et al. Large-scale international validation of the ADO index in subjects with COPD: an individual subject data analysis of 10 cohorts. BMJ Open. 2012;2:6. doi:10.1136/bmjopen-2012-002152

30. Quanjer PH, Tammeling GJ, Cotes JE, Pedersen OF, Peslin R, Yernault JC. Lung volumes and forced ventilatory flows. Report working party standardization of lung function tests, European Community for Steel and Coal. Official statement of the European Respiratory Society. Eur Respir J Suppl. 1993;16:5-40. doi:10.1183/ 09041950.005 s 1693

31. Keene SJ, Jordan RE, Franssen FM, et al. External validation of the updated ADO score in COPD patients from the Birmingham COPD cohort. Int J Chron Obstruct Pulmon Dis. 2019;14:2395-2407. doi:10.2147/COPD.S212381

32. Global strategy for the diagnosis, management, and prevention of chronic obstructive pulmonary lung disease 2013. Available from: http://aquirespi.fr/_pages/bpco/doc/gold.pdf?PHPSESSID= g8v35hvk7tb946qmm6nuv8loe0. Accessed December 31, 2013.

33. Oga T, Tsukino M, Hajiro T, Ikeda A, Nishimura K. Predictive properties of different multidimensional staging systems in patients with chronic obstructive pulmonary disease. Int $J$ Chron Obstruct Pulmon Dis. 2011;6:521-526. doi:10.2147/COPD.S24420 
34. Abu Hussein N, Ter Riet G, Schoenenberger L, et al. The ADO index as a predictor of two-year mortality in general practice-based chronic obstructive pulmonary disease cohorts. Respiration Int Rev Thoracic Dis. 2014;88(3):208-214. doi:10.1159/000363770

35. Carter JV, Pan J, Rai SN, Galandiuk S. ROC-ing along: evaluation and interpretation of receiver operating characteristic curves. Surgery. 2016;159(6):1638-1645. doi:10.1016/j.surg.2015.12.029

36. Fischer JE, Bachmann LM, Jaeschke R. A readers' guide to the interpretation of diagnostic test properties: clinical example of sepsis. Intensive Care Med. 2003;29(7):1043-1051. doi:10.1007/s00134003-1761-8

37. McGarvey LP, John M, Anderson JA, Zvarich M, Wise RA. Ascertainment of cause-specific mortality in COPD: operations of the TORCH Clinical Endpoint Committee. Thorax. 2007;62 (5):411-415. doi:10.1136/thx.2006.072348
38. Jo YS, Park S, Kim DK, Yoo CG, Lee CH. The cutoff point of clinical chronic obstructive pulmonary disease questionnaire for more symptomatic patients. BMC Pulm Med. 2018;18(1):38. doi:10.1186/s12890-018-0601-0

39. Sundh J, Stallberg B, Lisspers K, Kampe M, Janson C, Montgomery S. Comparison of the COPD Assessment Test (CAT) and the Clinical COPD Questionnaire (CCQ) in a clinical population. COPD. 2016;13(1):57-65. doi:10.3109/15412555.2015.1043426

40. Rich JT, Neely JG, Paniello RC, Voelker CC, Nussenbaum B, Wang EW. A practical guide to understanding Kaplan-Meier curves. Otolaryngol-Head Neck Surg. 2010;143(3):331-336. doi:10.1016/j. otohns.2010.05.007

International Journal of Chronic Obstructive Pulmonary Disease

Dovepress

\section{Publish your work in this journal}

The International Journal of COPD is an international, peer-reviewed journal of therapeutics and pharmacology focusing on concise rapid reporting of clinical studies and reviews in COPD. Special focus is given to the pathophysiological processes underlying the disease, intervention programs, patient focused education, and self management protocols. This journal is indexed on PubMed Central, MedLine and CAS. The manuscript management system is completely online and includes a very quick and fair peer-review system, which is all easy to use. Visit http://www.dovepress.com/testimonials.php to read real quotes from published authors.

Submit your manuscript here: https://www.dovepress.com/international-journal-of-chronic-obstructive-pulmonary-disease-journal 